\title{
Drivers of Health Policy Adoption: A political economy of HIV treatment policy
}

Matthew M. Kavanagh

Georgetown University Law Center, mk1915@law.georgetown.edu

Kalind Parish

Yale Law School

Somya Gupta

Independent

This paper can be downloaded free of charge from:

https://scholarship.law.georgetown.edu/facpub/2362

Matthew M. Kavanagh, Kalind Parish, Somya Gupta, "Drivers of health policy adoption: a political economy of HIV treatment policy," Policy \& Politics, 49 (2). https://doi.org/10.1332/ $030557321 \times 16108172938639$

This open-access article is brought to you by the Georgetown Law Library. Posted with permission of the author. Follow this and additional works at: https://scholarship.law.georgetown.edu/facpub

Part of the Health Law and Policy Commons 


\title{
Drivers of Health Policy Adoption: A political economy of HIV treatment policy
}

\author{
Matthew M. Kavanagh \\ Georgetown University, Washington, DC USA \\ Kalind Parish \\ Yale Law School, New Haven, CT USA \\ Somya Gupta \\ Independent, New Delhi, India
}

\section{Citation:}

Matthew M. Kavanagh, Kalind Parish, Somya Gupta, "Drivers of health policy adoption: a political economy of HIV treatment policy," Policy \& Politics, 49 (2)

https://doi.org/10.1332/030557321X16108172938639

\begin{abstract}
:
Why do some countries rapidly adopt policies suggested by scientific consensus while others are slow to do so? Through a mixed methods study, we show that the institutional political economy of countries is a stronger and more robust predictor of health policy adoption than either disease burden or national wealth. Our findings challenge expectations in scholarship and among many international actors that policy divergence is best addressed through greater evidence and dissemination channels. Our study of HIV treatment policies shows that factors such as the formal structures of government and the degree of racial and ethnic stratification in society predict the speed with which new medical science is translated into policy, while level of democracy does not. This provides important new insights about the drivers of policy transfer and diffusion and suggests new paths for practical efforts to secure adoption of "evidence-based" policies.
\end{abstract}




\section{Introduction}

Why do some countries rapidly adopt policies suggested by scientific consensus while others are slow to do so? Social and political institutions play a major role in high level social policy choices in both the global North and South. Significant variation exists in the mode and effectiveness of policymaking between countries as well as provision of public goods-variation linked to state capacity and the structures of both government and society. Much of health policy, however, is far less grand and far more technical than choices about, for example, the mode and level of welfare state social protection. Yet policies such as which medicines will be available in the health system or which standards of care will be practiced in public health facilities can have significant spending and distributional effects. Scientists, physicians, and the World Health Organization (WHO) spend significant effort identifying the optimal standards of medical care across a wide variety of health and disease areas. Translating changing scientific knowledge into policy can be critical for patients and for public health-yet the guideline policies that govern public health and medical practice often lag behind evidence; sometimes far behind. Efforts to address differences in adoption of such "evidence-based" policy at this more technical level focus on variation in ideas and the interpretation of evidence (Smith, 2013) alongside ability to finance new health interventions and relative urgency or priority of a given health issue. In this article, we suggest that background institutions of society and governance are as, if not more, important in policy choice, even at this more technical level.

HIV treatment is a particularly salient policy issue through which to examine this question. More than 75 million people have contracted the HIV virus worldwide, and over $40 \%$ of them have died (UNAIDS, 2020). An unprecedented international response to the HIV/AIDS pandemic has developed to address the factors to which policy divergence is often attributed: improving scientific evidence, clarifying interpretations of evidence for policymakers, creating awareness and dissemination channels, ensuring cost-benefit analyses, and providing resources to adopt new medical standards. However, even addressing all of these factors has been insufficient to secure rapid, equitable adoption of guidelines across countries and contexts. Especially in a globalized world, where policy diffusion is rapid, the persistence of cross-national 
differences in the policies governing standard medical treatments is a puzzle that cannot be explained by differences in knowledge or available resources for health. Recognizing instead that the idea of "evidence-based" policy is itself deeply political, we turn to national political institutions to better understand this.

We code and analyze HIV guidelines for 104 countries during a decade of shifting medical consensus and compare them to WHO recommendations, augmenting this evidence with qualitative interview data. Our findings show that the missing pieces of the puzzle-both in the literature and in the practice of entities like the WHO-are the political and economic institutions of society that health experts often ignore or assume to be idiosyncratic. Studies of policy diffusion, transfer, and translation provide important insights about the mechanisms through which policy ideas travel (Dolowitz and Marsh, 2000; Stone, 2016). We need, however, to grapple more fully with which structural factors shape when policy will travel and at what speed. Doing so provides insights not only into HIV treatment policy but into broader phenomena of interest to political science. We draw on literature in political economy and development, which helps provide a structural level of analysis, but which has not focused sufficiently on the ways in which health policy change is affected by economic and political institutions (Hall and Lamont, 2009).

Our analysis shows that key socio-political institutions are often decisive, while HIV prevalence and national wealth are poor predictors of policy change. Expectations generated in studies of policy change in higher level macro-politics do not always hold at this level, as the context of the policy issue interacts with these institutions. We show, perhaps counterintuitively, that where governments are structured with more checks on authority policy adoption moves faster-likely because of the power of political and social minorities to gain political priority. We also find evidence that policy coordination challenges in societies with high racial/ethnic stratification seep down to even technical health policy considerations. Our findings suggest that the governance of public health standards is a dynamic political process worthy of much greater attention by policy scholars. These political economy considerations help explain significant policy divergence, yet they have received far too little attention. We show here that these factors can be systematically evaluated. On that basis, we suggest a move beyond knowledge development and dissemination toward building political adoption strategies that address socio-political contexts and can more effectively speed the translation of science into policy. 


\section{HIV/AIDS Treatment-Science \& Policy Shifts}

HIV treatment provides a vivid illustration of the limits of the current understanding on adoption of technical policy. While HIV is in some ways exceptional (a global highly stigmatized pandemic, without a cure or vaccine), the response involves a range of standard-fare health policies about how medicines, practitioners, and facilities operate and which standard of care is expected. HIV treatment initiation, our area of inquiry, is thus generalizable to similar policies issued regularly by health regulators and ministries around the world on many diseases.

In the early days of the AIDS pandemic, death was a near certainty for people living with HIV. The development of Anti-Retroviral Treatment (ART) in 1996 revolutionized HIV medicine. While death rates quickly fell in wealthy countries, a different standard of care was initially adopted in lower income countries that did not include ART, justified by lack of infrastructure, cost, concerns about adherence, and political barriers. Activists and clinicians challenged this paradigm, overcoming each objection, and eventually medical policy converged to support treatment worldwide (Smith and Siplon, 2006).

Early medical consensus was to use to delay HIV treatment as long as possible to avoid high costs, side effects, and any unknown long-term effects of the drugs. ${ }^{1}$ Patients became "eligible" for HIV treatment after their immune systems reached a certain CD4 count, a measure of immune cells that might range from 500 to 1,600 cells $/ \mathrm{mm}^{3}$ among healthy adults (Williams et al., 2006). Most countries followed the lead of WHO, U.S., and European bodies, which initially set ART eligibility at CD4 200 (Ying et al., 2016).

As early as two decades ago, however, evidence began to show this policy was not optimal (Musicco et al., 1994). With better and more affordable medicines available, studies tested the benefits of earlier treatment and WHO policy advice on when to start treatment shifted in stages for HIV-positive adults-from eligibility at CD4 200 to 350, 500, and eventually to "treat all" regardless of CD4 count (see Figure 2). Specifically, evidence showed that starting treatment early to suppress the HIV virus has two major benefits. First, it improves the health of people living with HIV by reducing deaths and conditions from heart disease to cancer (START Study

\footnotetext{
${ }^{1}$ Note: this consensus reflected a tempering of the earliest "hit early, hit hard" strategies for ART (De Cock and ElSadr, 2013).
} 
Group, 2015). Second, it halts transmission of HIV, with recent data showing it is more effective than condoms (Rodger et al., 2016). Early ART was shown to be cost-effective, implementable at scale in difficult contexts, and the ethical and human rights issues were considered (Granich et al., 2008; Kavanagh et al., 2015; Havlir et al., 2020).

AIDS still kills nearly seven hundred thousand people each year and the translation of science into policy and practice has been identified a key gap in reducing mortality (Kavanagh, Katz and Holmes, 2020). It is hard to imagine a stronger evidence base than the well-funded randomized studies on HIV treatment described above. Alongside these studies, a massive global effort in information dissemination and resource mobilization has backed the translation of that science into policy: off-the-shelf recommendations from WHO to inform country policies, an entire UN agency in UNAIDS, and several multi-billion-dollar global funding mechanisms to support antiretroviral treatment programs in countries that cannot afford the cost.

Yet our analysis shows that policy choice among countries remained strikingly inconsistent (see Figure 1 below). Our analysis shows that many countries retained HIV treatment policies considered substantially out of date compared to WHO standards for years. Why?

As a dependent variable, this is particularly useful because there is little distance between policy and implementation. A change in guidelines is generally quickly taken up in front-line settings. The discretion of "street level bureaucrats" (Lipsky, 2010) is relatively limited as these policies shift the clinical standard drives the practice of clinicians-quickly more people start ART with all of the accompanying distributional and resource implications. Our qualitative interviews confirmed that governments consider these moves carefully because the policy shifts will so directly lead to changes with budget, human resources, and other implications.

\section{Policy Divergence: HIV Treatment and the Limits of Current Theory}

Health policy literature outlined below suggests that a complex relationship between three broad areas drives translation of science into policy: information and evidence; need and urgency; and resources and capacity. The case of HIV treatment provides a window into the limits of these factors, because even incredibly robust efforts have had very uneven success in securing universal adoption of the best HIV science. 
The idea of "evidence-based" medicine and health policy has gained widespread priority in recent decades (Smith, 2013). Many have argued the key to achieving uptake of the best science in policy is to bridge the gap between researchers and policymakers through "knowledge exchanges" and brokers policymakers find credible to help translate science into policy (Contandriopoulos et al., 2010). Analysis of cross-national variation in medical guidelines suggests countries choose different medical standards based on different available evidence and interpretation (Burgers et al., 2003). This explanation has been challenged as over-simplistic and missing key political realities (Smith, 2013). Scholarship in political science suggests international agencies and transnational norm consensus, in particular, drive political priority and policy diffusion (Gomez, 2011).

In HIV, it was argued that more and clearer studies would eliminate the disparity in HIV standards (De Cock and El-Sadr, 2013). Following closely the evolving studies, the WHO built global infrastructure around proposing optimal HIV treatment guidelines that included convening experts, analyzing evidence, and packaging it for extensive policy dissemination efforts. It is hard to think of an area of medicine with a more significant structure for knowledge dissemination than that built by WHO, UNAIDS, NIH, and other global AIDS initiatives.

Rapid adopters, from the US and France to Thailand and Malawi, quickly changed nationallevel medical guidelines along with new studies, sometimes years before the WHO advised it. Yet still, by 2017 just over half of countries had adapted their policies to fit WHO norms. Figure 1 below shows a wide range of policy choice-with quite a few countries using HIV treatment policies that were far out of date from current scientific evidence.

Figure 2 below shows the evolution of HIV treatment guidelines from WHO and in a few example countries between 2002, when WHO began issuing indicative guidelines, through 2017 by which point WHO had adopted "treat all" guidance, ending the period of evolving guidance on CD4 thresholds. This figure shows that global guidance and national policy moved generally, in step-wise fashion, toward "treat all" but with the significant divergence in the speed of adoption during this period when CD4 counts were a subject of divergent policy. 
Figure 1. HIV treatment guidelines, 2017

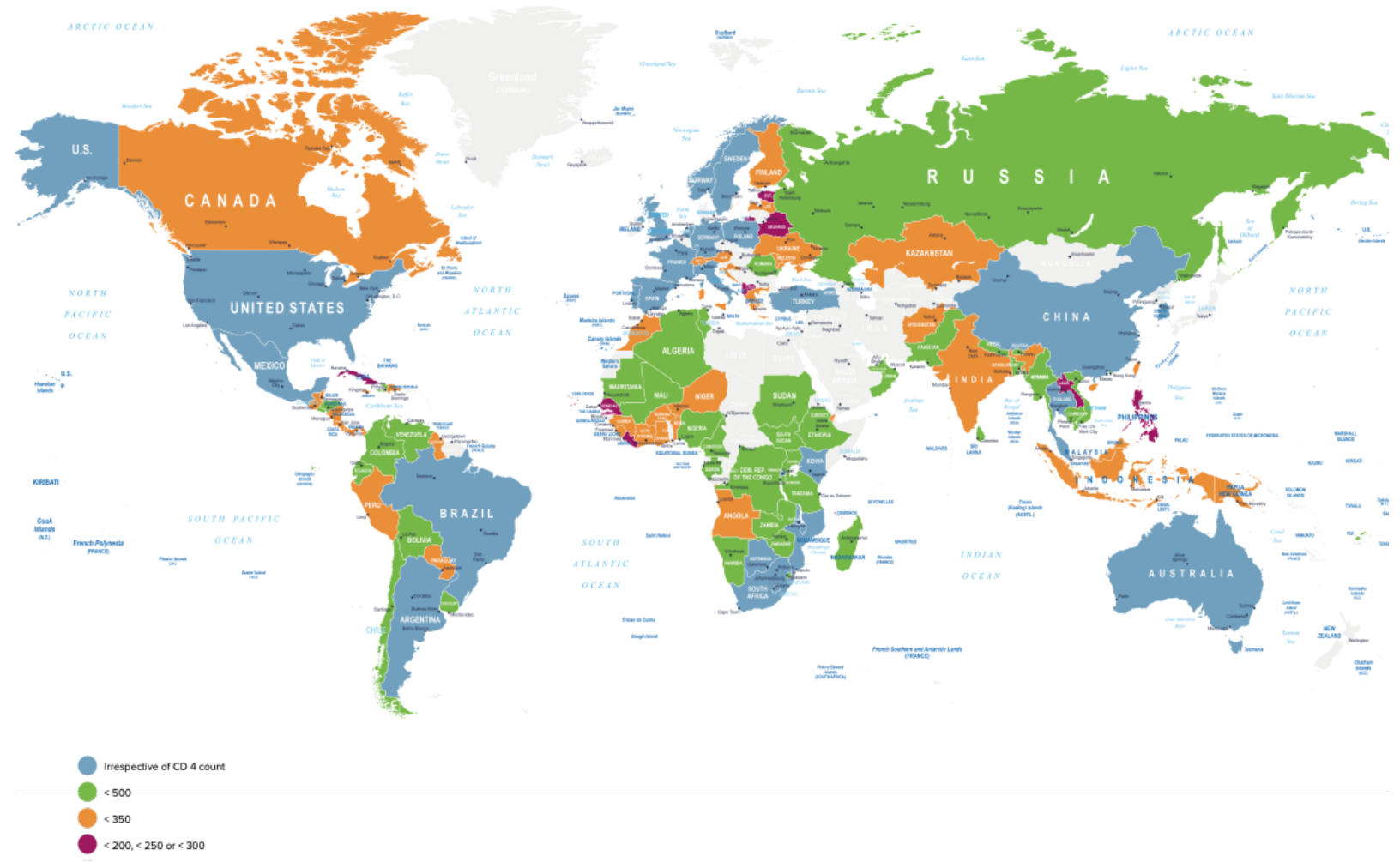

Figure 2. HIV Policy Evolution in Example Countries 2002-2017

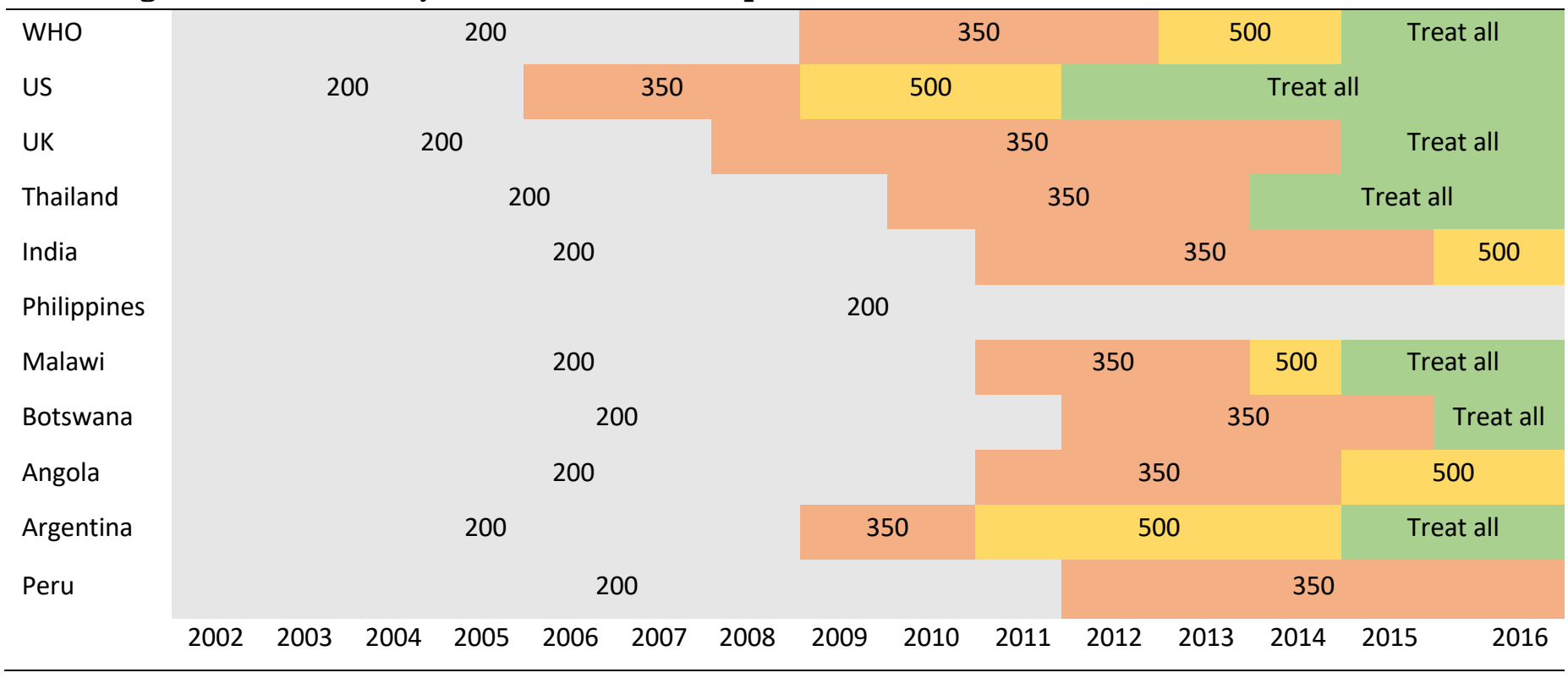


So why did such policy divergence continue? A variety of theories offer themselves.

One explanation is that policymakers act based on the size of the HIV epidemic. In weighing the relative merits of the adoption of a new standard of medical practice, countries with a greater burden of the given disease might move more quickly (Hecht et al., 2009). Agenda-setting literature supports the idea that larger portions of the population being affected and the urgency generated by a larger "problem" can drive quicker action (Shiffman et al., 2011).

Another reasonable explanation for divergence is that poorer countries will not adopt new guidelines, or will adopt them more slowly, because they simply cannot afford the cost of implementation (Hecht et al., 2009). Lower income countries might be less able, or might be perceived to be less able, to implement new medical guidelines. Yet on HIV, the UK, for example, has been a laggard even as poorer Turkey and Thailand have moved quickly. AIDS also has the largest infrastructure for international financing ever mobilized for health-with the Global Fund, U.S. President's Emergency Plan for AIDS Relief (PEPFAR), World Bank, and other major funding efforts focused on bridging the gap for low- and middle-income countries to afford HIV treatment.

A final possibility to consider is simply that policymaking on such technical issues is so complex that it is impossible to move toward convergence given idiosyncratic differences in perceptions of science, international political position, organization of AIDS movement groups and ministries of health, and dozens of other factors. Cohen, March and Olsen's 'garbage can' model of policymaking suggests that given the complexity in decision-making processes and contexts, it may be nearly impossible to predict policymaking (1972). Divergence in medical policy maybe inevitable given the complexity involved (Smith, 2013). Does that mean it is impossible to predict or change the effect of social and political factors?

Alternatively, we can turn to the growing body of scholarship critical of the idea of simplistic idea that any policy is based on evidence alone in a context where trade-offs between competing values are unavoidable (Weiss, 1979; Lin and Gibson, 2003). Rather than an apolitical process, the appeal to science and evidence has been revealed to be deeply political by promoting a choice amongst competing values (Parkhurst, 2017). In this context, rather than conformity we should expect that different political systems within countries will produce different policy 
outcomes-not because science is less understood, but because of differences in the actors, interests, and institutions involved in the policymaking process.

\section{A Political Economy of HIV Treatment Policy: is variation systematic?}

Certainly some in global health imply there may be little more that agencies like WHO can do to address divergence. We argue, however, that political factors can be considered far more systematically-that they are not simply part of the error term but can be evaluated to understand the factors that predict rapid adoption and those that suggest barriers.

In particular, we theorize that the institutions of state and society shape policy choice and affect the speed with which countries translate science into policy, including technical policy. The hypothesis that these factors affect policymaking is not unique (e.g. Pritchett \& Viarengo, 2010), but in such technical policies they seem to be considered part of the layers of complexity impervious to research and planning. We suggest the opposite.

HIV treatment policies reveal important aspects of broader phenomena in health policy. The existence of a massive global effort to stop HIV has addressed two key theories of policy adoption. While both accessible information and funding can surely be improved, it is hard to argue that either is determinative in the pace of policymaking. Continued disparities in policy push us to look deeper.

Insights from political science about "policy transfer" and "lesson drawing" have uncovered mechanisms through which policymakers use, or are coerced to use, knowledge, institutions, and ideas from one political system in another (Benson and Jordan, 2012). Dynamics of individual-level and interest group politics in policy adoption are also well established (GreenPedersen and Walgrave, 2014). Background institutional factors are understood to structure how these mechanisms take hold, but which of those background factors enable versus inhibit the adoption of science-backed policies is not clear.

The economic, political and social institutions of societies affect prosperity, wellbeing, and policy (Acemoglu and Robinson, 2012). Political economy frameworks can help in analyzing the question at hand-indeed, a few studies have looked at policy related to other aspects of HIV and health (Altman and Buse, 2012; Immergut, 1992). There is, however, insufficient work that 
brings this scholarship in comparative political science to bear on understanding when and why scientific evidence diffuses (or not). In particular, we focus on two pieces of the institutional environment we theorize have effect in the area of HIV.

First, we consider formal government institutions. Lijphart (Lijphart, 2012) argues "consensus" governance systems with few divisions in authority are more efficient, effective, and result in more generous social policies. The concept of "veto points" or "veto players" has developed to illustrate constraints on government policymaking that policy must pass in order to be enacted. Tsebelis suggests they show "capacity for policy change" (Tsebelis, 1995, p.292). The expectation is that more veto points will slow policy change. However, recent literature suggests the effect of veto points may not be straightforward. Rather than only blocks on change, veto points are a part of the strategic context in which policy negotiations occur and have a complex, issue-specific effect. More divided government, for example, can give greater power to minorities on isolated issues through providing a structural blocking power. Recent studies of pensions policy have shown more veto players can encourage compromise with minority interest (Bonoli 2000). Immergut \& Abou-Chadi show that where increasing the number of veto players does not increase the range of ideological difference, it may actually speed policy change (Immergut and Abou-Chadi, 2014). HIV guidelines are a comparatively technical policy area, of particular interest to minority groups, and do not fall along simplistic ideological lines.

Second is the question of ethnic politics. Political economy literature has shown that in more ethnically fragmented countries and communities, public goods provision is less robust and efficient (Alesina et al., 2003). It has been hypothesized that a variety of coordination challenges present in ethnically fractured societies undermine quick and efficient policymaking (Selway, 2015). Lieberman has shown that strong ethnic boundaries result in a politics of blame in HIV (Lieberman, 2009). There is little evidence, however, about whether these broad findings hold in more technical policymaking areas like HIV medical guidelines.

Some studies of international diffusion have suggested that adoption is driven by geographic proximity and "cognitive heuristics." That is, that bold policy changes catch the attention of nearby leaders who adopt them because they are available and fit their expectations of good policy rather than because they are well-considered (Weyland, 2009). We look for evidence for this theory as well. 


\section{Methodology}

To address this question we make use of a "nested analysis," which combines a quantitative statistical analysis with small-N qualitative work (Lieberman, 2005). This strategy allows us to investigate the question at these two different levels of analysis-reaching wide global coverage along with deeper in-country knowledge-and triangulate between the different types of causal leverage generated by each level. Health policymaking in a nation is complex and overdetermined-with multiple causal factors creating a given outcome. In this context, causal identification is particularly difficult without triangulating quantitative findings with qualitative data that can trace the policy processes.

\section{Quantitative Analysis of HIV Treatment Guidelines}

\section{$\underline{\text { Coding HIV Guidelines }}$}

We constructed a database of national HIV treatment guidelines through Internet searches, direct requests to experts and program managers, and unsolicited submissions. In sum, we collected 290 published national ART guidelines for adults and adolescents from 122 countries (representing 98\% of global HIV burden). Using this database, we abstracted from all these guidelines (a) the date (month and year) and (b) antiretroviral therapy eligibility criteria for asymptomatic people living with HIV. We coded guidelines based on three levels of eligibility criteria corresponding to recommendations from WHO, which advised countries to adopt ART at CD4 counts $<350$ cells/mm3 in 2009, $<500$ cells/mm3 in 2013 and irrespective of CD4 count in 2015. As national guidelines published before 2005 were often not available, we restricted the analysis to those three levels. For 18 countries, only the latest guideline or only the 2005-era guideline of CD4 $<200$ was available. These countries were excluded from further analysis.

For 104 countries, we determined the date of adoption that was consistent with a particular WHO recommendation. Using the WHO publication date (i.e. October 2009, June 2013 and September 2015), the adoption lag was calculated as the number of months' difference between date of WHO publication and date of adoption of that recommendation in the national guidelines. Higher positive values represent slower adopters while negative values represent adoption ahead of WHO policy change. For countries recommending ART at CD4 count <350, we calculated the time difference in adoption of WHO 2013 guidelines by using the reported 
date of the move as the date of adoption. Our dataset runs through 2017, so we also estimated the minimum time to movement to 2015 guidelines for those that had not done so by assuming, conservatively, that they moved by that date.

\section{Building a Model of the Political Economy Drivers of Guidelines Adoption}

To explore the idea that rational need drives policy adoption, we include HIV prevalence in our model. We include GDP per capita, because relative wealth and scientific knowledge are expected to affect policy processes in health, making adoption of technology possible through both purchasing power and health system capacity (Deaton, 2013). We hypothesize that the institutions of state and society systematically affect the speed with which policy is adopted, and we include three key political economy variables to test this. First, the most common political variable is relative electoral democracy, which is expected to support considered action for health and improved policy (Gerring, Thacker and Alfaro, 2012). Second, we include a measure of the "veto points" in a political system, which affect how decisions are made, including whether minority voices exercise influence. Finally, we include a variable to represent the racial and ethnic divisions in a society: Ethnolinguistic Fractionalization.

Below are the control variables and source used to construct the broader political economy model to test theories of rapid vs. delayed guidelines adoption and descriptive statistics for each.

Table 1. Summary Statistics

\begin{tabular}{lllll} 
Variable & Min & Mean & Max & Std. Deviation \\
\hline Ethno-Linguistic Fractionalization & 0.00 (scale 0 to 1) & 0.50 & 0.98 & 0.27 \\
Veto Points & 6 (scale 0 to 6) & 3.01 & 6 & 1.35 \\
Democracy & -9 (scale -10 to 10) & 5.28 & 10 & 5.00 \\
HIV Prevalence & $0.01 \%$ & $2.75 \%$ & $28.8 \%$ & $5.68 \%$ \\
GDP (Per Capita) & $\$ 190$ & $\$ 11,155$ & $\$ 102,910$ & $\$ 17,900$ \\
Months to CD4 = 350 & -104 months & 8.92 & 68 & 27.83 \\
Months to CD4 = 500 & -50 months & 13.49 & 42 & 19.46 \\
Months to CD4 = All & -51 months & 6.57 & 15 & 15.37 \\
\hline Sources: CD4 counts-authors coding; Ethno-Linguistic Fractionalization (Montalvo \& Reynal-Querol, \\
2005)PM; Veto Point/Political Constraint (Carlos Scartascini, Cesi Cruz, \& Philip Keefer, 2018) ; Democracy- \\
Polity Score (Marshall \& Jaggers, n.d.) ; HIV Prevalence (UNAIDS, 2017)), GDP Per Capita (World Bank \\
2017)
\end{tabular}

$\underline{\text { Statistical methods of analysis }}$ 
We use a Cox-Proportional Hazards Model to test our hypothesis that political variables provide stronger and more robust predictions of policy adoption (Cox, 1972). We believe this to be an appropriate modeling choice, as we are interested in the durability (or "survival time"-the amount of time it takes for an event to occur) of a country's old HIV policy when regressed against our covariates of interest. We chose a Cox Model over a Weibull Model due to the complexity of our distribution: while many countries do adopt quickly after a policy announcement, the majority do not. We are not comfortable making a potentially-heroic assumption about our distribution, and therefore chose a semi-parametric Cox Model. Given that guidelines adoption is an ongoing process, some type I censoring is present in our data, though the portion of observations censored is not worrying, with just $7.3 \%$ of observations censored in our core model (Lee and Wang, 2003)

We use country-level clustered standard errors to account for the fact that our observations are not perfectly independent. Clustering with small numbers of groups can be problematic. However, we far exceed the recommended number of 43 groups suggested by Angrist and Pischke (Angrist and Pischke, 2009). We also include a guidelines indicator variable to address potential bias from within-guidelines variation. While these efforts do eat our degrees of freedom, our model still returns robust and statistically significant results from our conservative estimates, which increases our confidence in their validity.

\section{Qualitative Process-Tracing}

At the second level, we conducted qualitative interviews for process tracing. Using a loosely constructed joint method framework, we set out to look for similar factors in decision-making among countries that adopted the best science of "early" initiation and how those factors differ from what occurs in the countries with "delayed" initiation. Sampling designs were structured to seek "causal process observations" to provide insight into the mechanism at work in these decisions (Collier, Brady and Seawright, 2010). In this context, a non-random sample of countries is justified in order to gain the extra context and information about processes that can only be accessed through examples directly relevant to the analysis. We created a purposive sample of 12 countries drawn from our database of countries seeking diversity in income level, HIV burden (adjusted for income level), and health system strength based on spending (> or $<8 \%$ GDP) and rankings described in Table 2. 
Table 2. Summary Statistics

\begin{tabular}{|c|c|c|c|c|c|c|}
\hline \multirow{3}{*}{$\begin{array}{c}\text { Early } \\
\text { Adopters }\end{array}$} & \multicolumn{2}{|c|}{ HIV Prevalence (adjusted) } & \multicolumn{2}{|c|}{ Per Capita health expenditure } & \multicolumn{2}{|c|}{$\begin{array}{l}\text { Health System ranking } \\
\text { (adjusted) }\end{array}$} \\
\hline & Higher & $\begin{array}{c}\text { Brazil, Malawi, Thailand, } \\
\text { U.S. }\end{array}$ & High & $\begin{array}{c}\text { Brazil, France, } \\
\text { Netherlands, U.S. }\end{array}$ & High & $\begin{array}{c}\text { France, Netherlands, } \\
\text { Thailand }\end{array}$ \\
\hline & Lower & France, Netherlands & Low & Malawi, Thailand & Low & Brazil, Malawi, U.S., \\
\hline \multirow{2}{*}{$\begin{array}{c}\text { Late } \\
\text { Adopters }\end{array}$} & Higher & $\begin{array}{c}\text { South Africa, Swaziland, } \\
\text { Uganda, Zambia }\end{array}$ & High & $\begin{array}{l}\text { Canada, South Africa, } \\
\text { Swaziland, Uganda, }\end{array}$ & High & Canada \\
\hline & Lower & Canada, India & Low & India, Zambia & Low & $\begin{array}{c}\text { Africa, Swaziland, } \\
\text { Uganda }\end{array}$ \\
\hline
\end{tabular}

Sources: (Institute of Medicine, 2013; Murray and Frenk, 2010; UNAIDS, 2017; World Bank, 2017)

$\underline{\text { Interview Strategy }}$

We conducted 25 semi-structured interviews in English (see Appendix for affiliations). Participants with first-hand knowledge of the decision-making process on HIV treatment policies for selected countries were sought out through snowball sampling and referrals from UN officials who track HIV policy. All interviewees were either government officials, intergovernmental organization staff, or academic experts in HIV and were members of the body that established the HIV guidelines for the country. Interviews were conducted on the sidelines of several international meetings on HIV between 2015 and 2019. We used a semi-structured interview process in which participants were asked to describe how decisions were made to change the HIV treatment eligibility guidelines, which specific people and actors inside and outside government were involved, and what factors were considered in reaching the decision. Content analysis coded for whether key areas of interest such as cost-benefit analysis or interpretation of scientific evidence were factors in the HIV treatment policy decision. The actors in the process were also coded in order to understand the role of different parts of government and the role of non-governmental and international actors. 


\section{Findings}

Table 3 provides the hazard ratios for the results of our Cox Proportional Hazard Models. Values above 1 represent a "positive" effect (faster adoption), and values between 0 and 1 represent a "negative" effect (slower adoption). The findings suggest that HIV prevalence serves as a poor predictor of WHO policy adoption. Wealth is also a poor predictor of policy adoption and is substantively small in its impact. However, Table 3 demonstrates that domestic politics play a critical role in the adoption of global HIV policy. We discuss the substantive implications along with data from the qualitative studies, grouping them into key insights about our core question of whether and which political factors systematically drive HIV treatment policy adoption.

Table 3 provides a conservative estimate of our argument, as there are a handful of nations which are extremely HIV-burdened. Political situations, however, are more normally distributed across countries. Figure 3 shows the distribution of HIV prevalence and ethno-linguistic fractionalization. Only 25 of our observations cross the $10 \%$ HIV prevalence threshold. HIV prevalence is not highly correlated with ethno-linguistic fractionalization, and the distribution of the latter variable is generally uniform. These findings suggest that a handful of highly-HIVburdened countries are increasing the effects of HIV prevalence in Table 3, while our political variables are not driven by such outliers.

\section{Table 3: Speed of HIV Treatment Policy Adoption, Cox Proportional Hazard Model}

(DV: months difference from WHO recommendation)

\begin{tabular}{|c|c|c|c|c|}
\hline & Model 1 & Model 2 & Model 3 & Model 4 \\
\hline Ethno-Linguistic & - & $0.367 * * *$ & $0.517 * *$ & $0.585^{*}$ \\
\hline Fractionalization & & $(0.293)^{\Omega}$ & $(0.307)$ & (3.120) \\
\hline \multirow{2}{*}{ Veto Points } & - & $1.223 * * *$ & $1.208 * * *$ & $1.260^{* * *}$ \\
\hline & & $(0.078)^{\Omega}$ & $(0.066)^{\Omega}$ & $(0.077)^{\Omega}$ \\
\hline \multirow[t]{2}{*}{ Democracy } & - & 0.984 & - & 0.979 \\
\hline & & $(0.018)$ & & $(0.020)$ \\
\hline \multirow[t]{2}{*}{ HIV Prevalence \% } & 1.015 & - & $1.021 *$ & $1.022 *$ \\
\hline & $(0.012)$ & & $(0.012)$ & $(0.012)$ \\
\hline GDP Per Capita ( $\$ 1000$ & $1.011^{*}$ & - & 1.003 & 1.005 \\
\hline units) & $(0.003)^{\Omega}$ & & $(0.006)^{\Omega}$ & $(0.006)^{\Omega}$ \\
\hline CD4 Guidelines & Included & Included & Included & Included \\
\hline $\mathrm{R}^{2}$ & 0.055 & 0.106 & 0.104 & 0.105 \\
\hline Num. obs. & 260 & 275 & 248 & 241 \\
\hline Wald Test (df) & $7.12(4)$ & $19.4(5)$ & $20.55(6)$ & $20.78(7)$ \\
\hline Wald Test $\mathrm{p}=$ & 0.13 & 0.00 & 0.00 & 0.00 \\
\hline
\end{tabular}


Figure 3. ELF and HIV Distribution: Four Categories

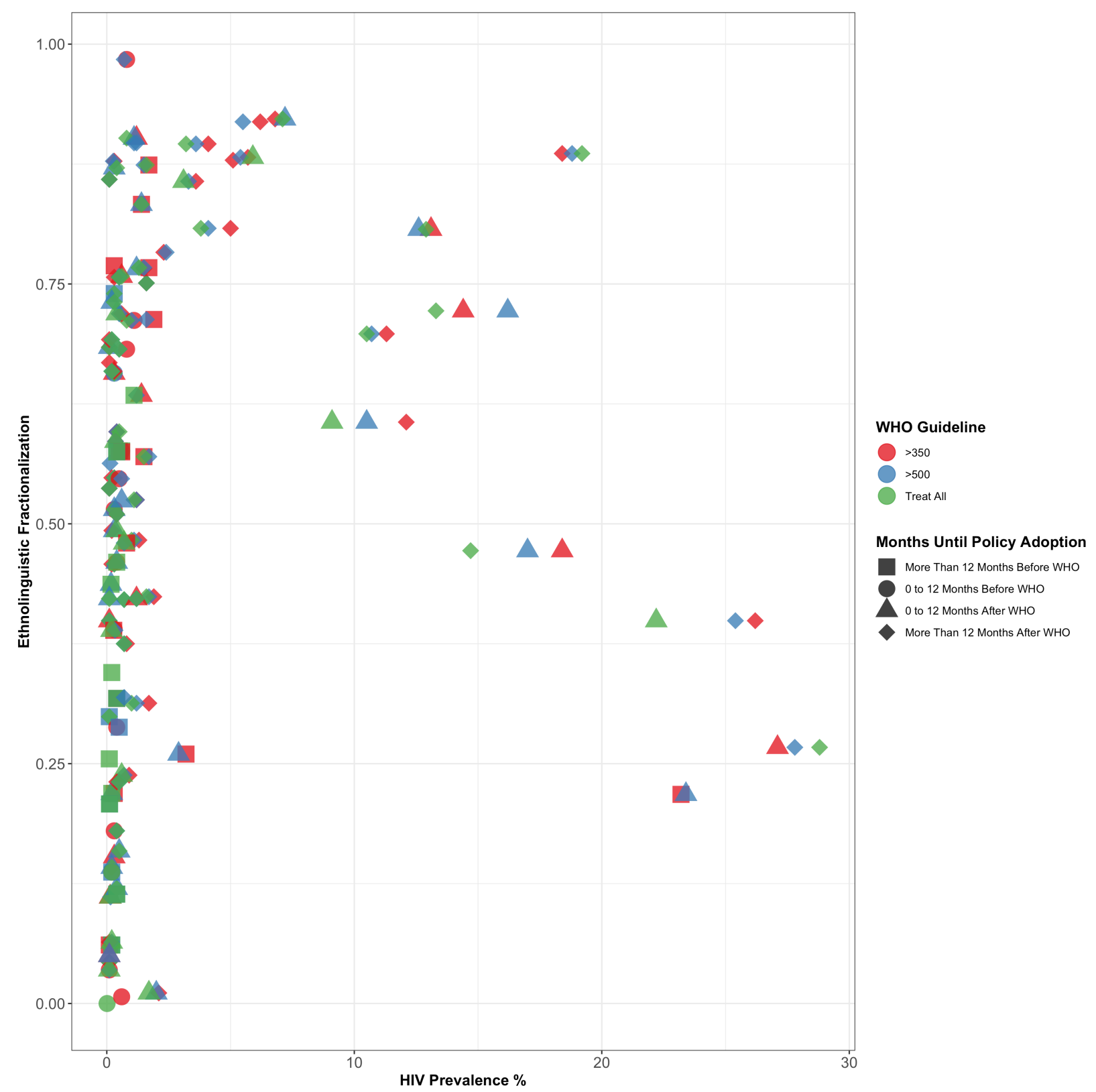

Table 4 provides an overview of how these outliers affect our analysis specific to Model 3. The results underscore how our political variables are consistent across countries and how HIV prevalence is only important in a select handful of nations for determining the speed of policy adoption. 
If outliers are strongly affecting our results, we should see the effects of our hazard ratios diminish as outliers are removed. We see such an affect for HIV prevalence, but not for our political variables. For ethno-linguistic fractionalization and veto points removing the top $10 \%$ changes speed of adoption by only $1 \%$ and $7 \%$ respectively per standard deviation. However, if we remove the $10 \%$ of countries with the largest HIV burdens, the standard deviation of the variable shrinks from 5.6 percentage points to 1.4 percentage points, and the effects of moving one standard deviation falls to $103 \%$ faster adoption, which is substantively tiny. Appendix A provides a number of controls for this argument.

\section{Table 4: Hazard Ratios for Interpretation of Model 3}

\begin{tabular}{|c|c|c|c|c|c|}
\hline & Hazard Ratio & Range & $\mu$ & Std. D. & $+1 \mathrm{SD} \Delta$ \\
\hline Ethno-Ling. Frac. & 0.517 & $0-0.984$ & 0.537 & 0.265 & $87 \%$ faster adoption \\
\hline Country Example: & & & Pakistan & $\rightarrow$ & Zambia \\
\hline W/O Top $10 \%$ of Scores & & $0-0.874$ & 0.472 & 0.242 & $88 \%$ faster adoption \\
\hline Country Example: & & & Zimbabwe & $\rightarrow$ & Burkina Faso \\
\hline Veto Points & 1.208 & $1-6$ & 3.073 & 1.354 & $128 \%$ faster adoption \\
\hline Country Example: & & & Croatia & $\rightarrow$ & Austria \\
\hline W/O Top $10 \%$ of Scores & & $1-5$ & 3.012 & 1.300 & $127 \%$ faster adoption \\
\hline Country Example: & & & Kenya & $\rightarrow$ & Poland \\
\hline HIV Prevalence \% & 1.021 & $0-29$ & 2.718 & 5.610 & $112 \%$ faster adoption \\
\hline Country Example: & & & South Sudan & $\rightarrow$ & Malawi \\
\hline W/O Top $10 \%$ of Burden & & $0-9.1$ & 0.976 & 1.357 & $103 \%$ faster adoption \\
\hline Country Example & & & Burundi & $\rightarrow$ & Angola \\
\hline
\end{tabular}

We have five key findings:

\section{Neither disease burden nor wealth is a good predictor of policy change; but politics shapes the weighing of evidence and costs.}

Our analysis shows that empirical relationship between HIV prevalence and the speed of adoption is limited. HIV Prevalence has, at best, a weak statistical relationship with WHO policy adoption. In Table 3, Model 3 the hazard ratio for HIV prevalence is merely 1.021, meaning that for a one percentage point increase in prevalence (a large increase) we would expect the speed of policy alignment to WHO recommendations to be to $102 \%$. Our data show that HIV prevalence is only substantively important for a small fraction of high-burden nations, and even in such locations, the effects of HIV burden are not as powerful as political considerations. The nations 
with highest HIV rates drive the size and statistical significance of the HIV prevalence variable as we show in Table 5 of Appendix A where the substantive effect of the variable shrinks and loses statistical significance. Our data therefore do not suggest countries are making decisions about how quickly to shift their guidelines based on how important HIV is to the health of populations. Nor are agendas being systematically influenced by the number of people living with HIV in a polity. Our qualitative analysis backs this up-even as guidelines documents sometimes cite prevalence, none of our informants report considering the relative burden of disease when writing the guidelines.

Similarly, GDP per capita is also a poor predictor of adoption speed. Wealth is only significant in Model 1 (which lacks any political variables), and the effect is small: for every additional $\$ 1,000$ of per capita GDP, the expected adoption rate only increases by $1 \%$. A one standard deviation increase $(\$ 18,000)$ per capita will only increase adoption speed by $18 \%$. In our other models the variable loses statistical significance.

Meanwhile, interviewees described remarkably little variation in their interpretation of the evidence-suggesting WHO and UNAIDS efforts to disseminate science are either very effective or unnecessary. Either way, all interviewees reported a discussion of the medical evidence but despite some slight differences in how countries weighed the evidence, each reported that by the time the WHO changed its guidelines, the science was fairly clear. The WHO was seen as a credible source upon which to depend for summaries of the evidence.

In our interviews, only some guidelines processes considered cost. Our quantitative study shows that the effects of wealth are substantively small and statistically inconsistent. Perhaps not surprisingly, guidelines processes in wealthy countries rarely considered cost while those in low income countries did so regularly. "Cost has been a main determinant and driver of determining how we move," as one interview participant from Africa put it (Interview 11). This might seem obvious-poorer countries have less to spend and thus consider costs. Indeed, discussion in public health literature on medical guidelines does portray cost-effectiveness as one part of a good guidelines-writing process, though not without controversy (Shaneyfelt, Mayo-Smith and Rothwangl, 1999). Yet in practice, cost was not considered at all in the writing of guidelines on when to start in the U.S. or France (interviews 7 and 8). In British Columbia, Canada, cost was considered-in line with the country's unified payer structure of care-but only in order to justify 
increased public sector support for outreach services, not whether to change medical guidelines (interview 6).

In Global South countries, on the other hand, data suggest the consideration of costs was critical-but political than technocratic. The process was largely not a formal cost-benefit analysis. No interviewee reported using actual estimates of cost-effectiveness of immediate initiation. In fact, data show that early initiation of ART is cost-effective in low- and middle-income settings. But this is not what was being considered. Instead, Southern processes largely started with the question of medical evidence and reached tentative conclusions that supported immediate initiation. They then defaulted to non-optimal treatment (initiation at higher CD4 counts) after considering the simpler question of whether sufficient funding would be made available in the near future.

\section{Democracy does not speed adoption}

While democratic theory suggests that information to and from government, incentives to deliver public goods, and mechanisms to punish slow response could improve health policy, our data do not show electoral democracy as a significant factor in HIV guidelines adoption. Democracy, represented here as a scale from autocratic to democratic, is never statistically significant, nor is it substantively large. This quantitative finding is supported by our interviews: guidelines are not legislated, nor do most elected officials play a formal role in guidelines processes, which move through technocratic and executive decision-making structures. The free flow of scientific evidence was critical to processes, but it was not particularly inhibited by limited electoral democracy. In Thailand, for example, even under military government, the guidelines process was efficient and bold action was encouraged.

\section{Increased veto points are associated with faster policy change}

One of the most interesting finding in our data is that greater numbers of veto points in

government are strongly associated with faster policy adoption. The size of the effect of moving from a system with little political constraint (e.g. Fiji; Kazakhstan; Madagascar; Morocco; et cetera) to high levels of veto player constraints (Germany; Sweden; et cetera) is associated with an increase in adoption speeds from 204\% in Model 3 (the smallest estimate) to 230\% in Model 
4 (the largest estimate). Table 4 shows a single standard deviation increase of slightly over one veto point increases adoption speed by $128 \%$ in Model 3.

On its face this may seem counterintuitive-with greater separation of power imagined to slow policymaking. Our findings make sense, however, if one takes into consideration the specific micro-politics of the issue. Changing HIV guidelines is, in part, a decision to increase expenditure on medicines for an often socially-disfavored group. What divided power does do is create opportunities for minority groups. Immergut and Abou-Chadi find a similar phenomenon where pension policy changes faster in contexts of greater veto points (Immergut and AbouChadi, 2014).

Data from our interviews revealed that HIV treatment policy is only rarely decided primarily in the macro-political sphere. Instead it is discussed in smaller, technocratic venues. In the U.S., for example, guidelines committees are semi-independent voting bodies-made up of clinicians, researchers, and patients housed within the Department of Health and Human Services. In contrast, in Rwanda, Uganda and India, for example, writing guidelines is an official government process and are approved after a formal government process involving the Minister of Health. In several countries (e.g. Rwanda), the Ministry of Finance is also involved. Finally, in each of the African countries, the major international donors-the U.S., U.K., and others-also sit on the technical committee and have influence through their willingness to support increased HIV treatment costs.

Our interviews revealed a mechanism through which this may work. We know that some political systems give more opportunities to disfavored social and political minorities to access to political system than others (Baumgartner and Jones, 2015). It may be more likely that people living with HIV and communities most affected by the disease-which disproportionately affects sexual minorities, sex workers, people who use drugs, young women in sub-Saharan Africa, and other marginalized groups-will be able to build political power to affect this technocratic deliberation in a structure with multiple veto points. In Swaziland, a late adopter, power is highly centralized-which would theoretically make the process faster. However, the process was slowed by bureaucratic processes and questions from the finance ministry. With little pressure from outside, in particular no engagement from political actors from, the low priority government gave to this question meant uptake was slow. Botswana, where there are also relatively fewer veto players, has a similar situation where treatment guidelines were hung up 
on bureaucratic debates within the ministry. On the other hand, in the U.S. with multiple veto points, political priority on reviewing scientific evidence to produce frequent updates in HIV treatment policy reflects the comparative power of the minority of people most affected by HIV. This is perhaps best captured in the words of one respondent, who noted that for a policy issue like HIV treatment guidelines, "in our process it actually only takes one or two Congress Members who care about this to inquire and it creates momentum, unlike passing a bill." (Interview 23) While it has been claimed that systems with fewer veto points move policy more rapidly, in political systems with many veto points, politicians have an incentive to respond to smaller political groups, and members of minority parties can exercise outsized power to get attention for their issue. Thus it is in these systems that political attention is most likely to be secured for HIV and to spark action.

\section{Social structures matter-racial \& ethnic stratification slows adoption}

In our quantitative results, we show that adoption of science-based HIV policies is slower in contexts with complex racial/ethnic divisions. In Model 4, our smallest estimate of all our models, a country with high ethno-linguistic fractionalization (Papua New Guinea is closest with a score of 0.984 , with Uganda and Tanzania also scoring high) would adopt at a speed only $48.3 \%$ as fast as a country with minimal fractionalization (e.g. the Maldives, although Japan and South Korea come very close to scores of zero). In other words, highly-fractionalized countries will adopt at about half the speed of countries with low fractionalization scores. The variable is statistically significant across all of our models, and a full-swing in ethno-linguistic fractionalization in Model 2 would result in a $62 \%$ slower adoption rate.

In contexts of high ethnic fractionalization, identification of people living with HIV as the "other" is likely to undercut efforts to speed the adoption of science for a disease cast in ethnic terms and associated with already stigmatized groups, even as public health officials tend to see and talk about the medical evidence as neutral. Reports of limited political power and lack of consensus on AIDS from our respondents in delayed-adopting countries with known deep ethnic divisions suggests this mechanism is at work in HIV treatment guidelines, even as respondents did not explicitly cite ethnic politics per se. "Up to date science for people living with AIDS is just not a priority for government, even with all the donor attention, because of the stigma associated with those living with the disease, which is why it's taken years and even court cases 
to force the issue," reported one informant from India, a country with high ethnic fractionalization (Interview 21). While our study was not designed to assess the national legal environment, future research linking criminalization and the polticial power of stigmatized groups may reveal further socio-political drivers

Recognizing that in some countries the guidelines process will be injected with racial politics can be the first step toward a strategy that takes this into account when building political priority for health policy change.

\section{International Factors: push and pull of WHO, aid agencies, and neighboring countries}

A final factor that emerged very clearly in our qualitative data was the role of international actors, especially the WHO. While it is countries themselves that adopt medical practice guidelines, WHO has published recommended guidelines since 2002. It is substantively notable that adoption of previous guidelines was significant in most of our statistical models-adoption of a previous guideline slowed adoption of the subsequent guideline. This suggests there may be a cost to WHO issuing recommendations in close succession, though more work is needed to understand this fully.

Our interview data show that in addition to differences in veto players and how costs are considered, the role of the WHO was different between North and South, which supports findings in previous work (Parkhurst et al., 2010). In the North, the International AIDS Society (IAS) recommendations, crafted by an independent association of HIV physicians, carried scientific weight-and some countries, like the Netherlands, adopted them nearly in full-largely based on the prestige of the scientists on the IAS panel. In the North, the WHO was largely irrelevant. As one interview participant from France put it, "we decided we would not be influenced by what the WHO was saying” (Interview 7).

Southern guideline writers, on the other hand, viewed the WHO guidelines as critical-with several participants calling it the "gold standard." In some cases WHO also became a barrier to "treat all" policies for several years, when the IAS and U.S. guidelines moved to "treat all" but WHO had not. Concerns about costs and feasibility sidetracked WHO debates for several years, in an echo of fights over early differential standards of HIV treatment in North and South. 
Nearly all of the Southern interview participants expressed a sense, during much of this period, that immediate initiation was medically advisable for patients well before their policy changed, and many knew of the IAS guidelines. But going beyond WHO's recommendation put them in a precarious position because of how it was viewed by the political veto players in their process. "How can I tell the ministry of Finance that we want to do more than the WHO says?" one put it (Interview 17). Others expressed the sense that international donors would not finance programs beyond WHO recommendations. "There was a feeling that if WHO says it, then it's a human right," but beyond that was questionable science and politics (Interview 10).

Donor agencies, meanwhile, played a significant role in the global South. Dependence on donors to fund policy adoption slowed the process. Donor agencies in HIV have had a significant impact, not just on which decisions were made but on governance structures and practices (Kavanagh and Chen, 2019). Global Fund to Fight AIDS, TB, and Malaria, for example, has required countries to create Country Coordinating Mechanisms that involve cross-sectoral government and non-governmental participation. These governance structures increase the influence of international actors from Geneva, Washington, and other donor capitals. Interview participants reported that reluctance to absorb the expanded costs of shifting policies, especially at the Global Fund, led countries to "pilot" moves to provide earlier ART instead of fully adopting updated guidelines for several years. There are limits to this influence, however. Some countries like Malawi pushed against that reluctance and cut new ground-adopting immediate treatment for all pregnant women and then "treat all" before the WHO. A notable trend can be seen in our data, however, in 2016, when the U.S. PEPFAR program, the largest single HIV donor in East and Southern Africa, made it policy to strongly encourage all countries to shift to "treat all" and made funding available to support this shift. Within the year, most countries in the region shifted or began to shift their guidelines.

Finally, we reviewed the question of whether countries are learning from each other-either consciously or through geographic proximity and the availability of good policy as suggested by Weyland (2009). We constructed a measure of geographic proximity to test whether the speed of adoption of a country's neighbors (measured as average speed of adoption of all bordering countries) was a significant predictor of adoption and found it was not-neither by itself nor in our core model (Table 8, Appendix A). This aligns with a broad review of countries. For example, while there was some clustering of rapid adopters, it does not tell a clear story. France and the Netherlands are close in geography and take pride in being seen as leaders in HIV. Both were 
rapid adopters. But while Malawi was an early adopter, only a few of its neighbors were. Southeast Asia is home to the early-adopting Thailand but all of its neighbors have been far slower-with Laos, Indonesia, and Philippines among the biggest outliers in slow uptake. While the U.S. adopted quickly, Canada lagged. Our qualitative data, meanwhile, do not suggest geographic mimicry per se. Three interview subjects-from France, Thailand, and Brazilreported policies of other countries came up in their policy-making process, but all three cited the U.S.. This is not surprising given the dominant U.S. role in both geopolitics and in HIV policy, but it does not suggest neighborly learning. It does hint, however, that constructivist explanations of mimicry of positive leadership (regardless of geography) may be at play, which future research might be designed to unpack.

\section{Limitations}

These findings break new ground by testing theories in public policy and political economy on a unique dataset of policy guidelines that enable testing of the speed of policy transfer. There are, however, limitations in our approach. Guidelines data cover the vast majority of the HIV burden, which gives us confidence in generalizing from their findings. They are nonetheless incomplete and subject to bias from incomplete data. The data also represent a short period of time, since comparable guidelines are only available for the past approximately 15 years. Our

qualitative data make up for some of these limitations, but they are limited in reach to 12 countries. Further research both on HIV treatment guidelines and on other similar policies will help test the degree to which our findings can be informative or applicable outside the field of HIV.

\section{Conclusion}

Through a mixed methods study, we show that the institutional political economy of countries is a stronger and more robust predictor of health policy adoption than either disease burden or national wealth. Our findings challenge expectations in scholarship and among many international actors that policy divergence and inequities are best addressed through greater evidence and dissemination channels. Our study of HIV treatment policies shows that factors such as the formal structures of government and the degree of racial and ethnic stratification in society predict the speed with which new medical science is translated into policy, while neither the level of democracy nor the policy choices of neighboring countries do so. This 
provides important new insights about the conditions under which mechanisms described in political science for policy transfer and diffusion will work quickly, slowly, or not at all. That these factors are systematic, rather than random, has implications for agencies such as WHO and UNAIDS with a mission to advance evidence-based policymaking and rapid diffusion of science. Identifying policy champions and messages to cut across racial and ethnic cleavages in diverse societies could be important. Distinct political strategies are needed for highly centralized states versus those with more dispersed power, where engaging entrepreneurial minority political leaders may have greater power. Building diffusion strategies, messages, and policy networks that are tailored to national political context is possible when systematic sociopolitical factors are identified. These political strategies may prove as important as the collation and dissemination of evidence itself for ensuring widespread adoption of medical policies based on evolving science. 


\section{References}

Acemoglu, D. and Robinson, J.A. (2012) Why nations fail: the origins of power, prosperity, and poverty. New York: Penguin/Random House Crown Publishing.

Alesina, A., Devleeschauwer, A., Easterly, W., Kurlat, S. and Wacziarg, R. (2003) Fractionalization. Journal of Economic growth. 8 (2), pp. 155-194.

Altman, D. and Buse, K. (2012) Thinking politically about HIV: political analysis and action in response to AIDS. Contemporary Politics. 18 (2), pp. 127-140.

Angrist, J.D. and Pischke, J.-S. (2009) Mostly harmless econometrics: An empiricist's companion. (no place) Princeton university press.

Baumgartner, F.R. and Jones, B.D. (2015) The politics of information: Problem definition and the course of public policy in America. (no place) University of Chicago Press.

Benson, D. and Jordan, A. (2012) Policy transfer research: still evolving, not yet through? Political studies review. 10 (3), pp. 333-338.

Burgers, J.S., Grol, R., Klazinga, N., Makela, M. and Zaat, J. (2003) Towards evidence-based clinical practice: an international survey of 18 clinical guideline programs. International Journal for Quality in Health Care. 15 (1), pp. 31-045.

Cohen, M.D., March, J.G. and Olsen, J.P. (1972) A garbage can model of organizational choice. Administrative science quarterly. pp. 1-25.

Collier, D., Brady, H.E. and Seawright, J. (2010) Sources of Leverage in Causal Inference. In: Rethinking Social Inquiry. (no place) Rowman \& Littlefield Publishers. pp. 161-200.

Contandriopoulos, D., Lemire, M., Dennis, J.L. and Tremblay, É. (2010) Knowledge exchange processes in organizations and policy arenas: a narrative systematic review of the literature. Milbank Quarterly. 88 (4), pp. $444-483$.

Cox, D. (1972) Regression models and life tables (with discussion). Journal of the Royal Statistical Society. 34 (2), pp. $187-220$

De Cock, K.M. and El-Sadr, W.M. (2013) When to start ART in Africa-an urgent research priority. New England Journal of Medicine. 368 (10), pp. 886-889.

Deaton, A. (2013) The great escape: Health, wealth, and the origins of inequality. (no place) Princeton University Press.

Dolowitz, D.P. and Marsh, D. (2000) Learning from abroad: The role of policy transfer in contemporary policymaking. Governance. 13 (1), pp. 5-23.

Gerring, J., Thacker, S.C. and Alfaro, R. (2012) Democracy and human development. The Journal of Politics. 74 (01), pp. 1-17.

Gomez, E.J. (2011) How Brazil outpaced the United States when it came to AIDS. Journal of health politics, policy and law. 36 (2), pp. 317-352.

Granich, R., Gilks, C.F., Dye, C., De Cock, K.M. and Williams, B.G. (2008) Universal voluntary HIV testing with immediate antiretroviral therapy as a strategy for elimination of HIV transmission. The Lancet. 373 (9657), pp. 48-57.

Green-Pedersen, C. and Walgrave, S. (2014) Agenda setting, policies, and political systems: a comparative approach. (no place) University of Chicago Press. 
Hall, P.A. and Lamont, M. (2009) Successful societies: How institutions and culture affect health. (no place) Cambridge University Press.

Havlir, D., Lockman, S., Ayles, H., Larmarange, J., Chamie, G., Gaolathe, T., Iwuji, C., Fidler, S., Kamya, M. and Floyd, S. (2020) What do the Universal Test and Treat trials tell us about the path to HIV epidemic control? Journal of the International AIDS Society. 23 (2), pp. e25455.

Hecht, R., Bollinger, L., Stover, J., McGreevey, W., Muhib, F., Madavo, C.E. and de Ferranti, D. (2009) Critical choices in financing the response to the global HIV/AIDS pandemic. Health affairs. 28 (6), pp. 1591-1605.

Immergut, E.M. (1992) Health politics: interests and institutions in Western Europe. (no place) Cambridge University Press.

Immergut, E.M. and Abou-Chadi, T. (2014) How electoral vulnerability affects pension politics: Introducing a concept, measure and empirical application. European Journal of Political Research. 53 (2), pp. 269-287.

Kavanagh, M.M. and Chen, L. (2019) Governance and Health Aid from the Global Fund: Effects Beyond Fighting Disease. Annals of Global Health. 85 (1), .

Kavanagh, M.M., Cohn, J., Mabote, L., Meier, B.M., Williams, B., Russell, A., Sikwese, K. and Baker, B.K. (2015) Evolving Human Rights and the Science of Antiretroviral Medicine. Health \& Human Rights Journal. 17 (1), pp. 76-90.

Kavanagh, M.M., Katz, I.T. and Holmes, C.B. (2020) Reckoning with mortality: global health, HIV, and the politics of data. The Lancet. 396 (10246), pp. 288-290.

Lee, E.T. and Wang, J. (2003) Statistical Methods for Survival Data Analysis. (no place) John Wiley \& Sons.

Lieberman, E.S. (2009) Boundaries of contagion: how ethnic politics have shaped government responses to AIDS. (no place) Princeton University Press.

Lieberman, E.S. (2005) Nested analysis as a mixed-method strategy for comparative research. American Political Science Review. 99 (03), pp. 435-452.

Lijphart, A. (2012) Patterns of democracy: Government forms and performance in thirty-six countries. (no place) Yale University Press.

Lin, V. and Gibson, B. (2003) Evidence-based health policy: problems and possibilities. (no place) Oxford University Press.

Lipsky, M. (2010) Street-level bureaucracy, 30th ann. Ed.: dilemmas of the individual in public service. (no place) Russell Sage Foundation.

Musicco, M., Lazzarin, A., Nicolosi, A., Gasparini, M., Costigliola, P., Arici, C. and Saracco, A. (1994) Antiretroviral treatment of men infected with human immunodeficiency virus type 1 reduces the incidence of heterosexual transmission. Archives of Internal Medicine. 154 (17), pp. 1971-1976.

Parkhurst, J. (2017) The politics of evidence: from evidence-based policy to the good governance of evidence. (no place) Routledge.

Parkhurst, J.O., Hyde, A., South, A., Brehmer, L., Miller, A. and Newell, J.N. (2010) Improving communication of research findings: identifying the sources of information most important to national disease control officers in low-and middle-income countries. Tropical Medicine \& International Health. 15 (10), pp. 1252-1255.

Pritchett, L. and Viarengo, M. (2010) Explaining the Cross-national Time Series Variation in Life Expectancy: Income, Women's Education Shifts and what Else? (no place) United Nations Development Programme.

Rodger, A.J., Cambiano, V., Bruun, T., Vernazza, P., Collins, S., Van Lunzen, J., Corbelli, G.M., Estrada, V., Geretti, A.M. and Beloukas, A. (2016) Sexual activity without condoms and risk of HIV transmission in 
serodifferent couples when the HIV-positive partner is using suppressive antiretroviral therapy. Journal of the American Medical Association. 316 (2), pp. 171-181.

Selway, J.S. (2015) Coalitions of the Wellbeing: How Electoral Rules and Ethnic Politics Shape Health Policy in Developing Countries. (no place) Cambridge University Press.

Shaneyfelt, T.M., Mayo-Smith, M.F. and Rothwangl, J. (1999) Are guidelines following guidelines? Journal of the American Medical Association. 281 (20), pp. 1900-1905.

Shiffman, J., Pump, B., Hinchcliff, R., Poulos, R., Ivers, R.Q., Senserrick, T., Wallsten, K., Elberse, J.E., Pittens, C.A.C.M. and de Cock Buning, T. (2011) Agenda setting in public health policy. Policy Studies Journal. 39 pp. 1-12.

Smith, K. (2013) Beyond evidence based policy in public health: The interplay of ideas. (no place) Springer.

Smith, R.A. and Siplon, P.D. (2006) Drugs into bodies: global AIDS treatment activism. (no place) Praeger Publishers.

START Study Group (2015) Initiation of Antiretroviral Therapy in Early Asymptomatic HIV Infection. New England Journal of Medicine. pp. 150720091517005. doi:10.1056/NEJMoa1506816.

Stone, D. (2016) Understanding the transfer of policy failure: bricolage, experimentalism and translation. Policy \& Politics.

Tsebelis, G. (1995) Decision making in political systems: Veto players in presidentialism, parliamentarism, multicameralism and multipartyism. British journal of political science. 25 (3), pp. 289-325.

UNAIDS (2020) 2020 Global AIDS Update: Seizing the moment [online]. Available from: https://www.unaids.org/en/resources/documents/2020/global-aids-report [Accessed 2 August 2020].

Weiss, C.H. (1979) The many meanings of research utilization. Public administration review. 39 (5), pp. 426-431.

Weyland, K. (2009) Bounded rationality and policy diffusion: social sector reform in Latin America. (no place) Princeton University Press.

Williams, B.G., Korenromp, E.L., Gouws, E., Schmid, G.P., Auvert, B. and Dye, C. (2006) HIV infection, antiretroviral therapy, and CD4+ cell count distributions in African populations. The Journal of infectious diseases. 194 (10), pp. 1450-1458.

Ying, R., Granich, R.M., Gupta, S. and Williams, B.G. (2016) CD4 cell count: declining value for antiretroviral therapy eligibility. Clinical Infectious Diseases. 62 (8), pp. 1022-1028. 


\section{Appendix A: Robustness Checks for Outlier Control Sampling and Neighbor Adoption}

We ran three additional sets of regressions using different samples. In Table 5, we removed the top $10 \%$ of countries with the highest HIV burdens to reduce the range of the HIV prevalence from $0-28.8 \%$ to $0-9.1 \%$. HIV Prevalence loses statistical significance and the substantive impact is actually lessened when we consider that the possible range of variable movement is lower.

Table 5: Outlier Controls for HIV Prevalence

\begin{tabular}{lcccc}
\multicolumn{4}{l}{ Hazard Models Excluding Top $10 \%$ of HIV } & Burdened Countries \\
\hline \hline & Model 1 & Model 2 & Model 3 & Model 4 \\
\hline Ethno-Lingustic & - & $0.503^{* *}$ & $0.465^{* *}$ & $0.519^{*}$ \\
Fractionalization & & $(0.325)^{\Omega}$ & $(0.360)^{\Omega}$ & $(0.361)^{\Omega}$ \\
Veto Points & - & $1.266^{* * *}$ & $1.200^{* * *}$ & $1.237^{* *}$ \\
& & $(0.086)^{\Omega}$ & $(0.070)^{\Omega}$ & $(0.086)^{\Omega}$ \\
Democracy & - & 0.985 & - & 0.985 \\
& & $(0.021)$ & & $(0.022)$ \\
HIV Prevalence $\%$ & 0.996 & - & 1.059 & 1.057 \\
& $(0.054)$ & & $(0.059)$ & $(0.061)$ \\
GDP Per Capita & $1.010^{*}$ & - & 1.004 & 1.004 \\
(\$1000 units) & $(0.006)^{\Omega}$ & & $(0.006)^{\Omega}$ & $(0.006)^{\Omega}$ \\
CD4 Guidelines & Included & Included & Included & Included \\
\hline R ${ }^{2}$ & 0.054 & 0.098 & 0.109 & 0.108 \\
Num. events & 172 & 167 & 172 & 167 \\
Num. obs. & 222 & 215 & 222 & 215 \\
Wald test $($ df $)$ & $5.54(4)$ & $14.96(5)$ & $20.09(6)$ & $19.52(7)$ \\
Wald test p $=$ & 0.24 & 0.01 & 0.00 & 0.01 \\
\hline${ }^{* * *} p<0.01,{ }^{* *} p<0.05,{ }^{*} p<0.10$, hazard ratios, (SE) or $\Omega=($ Robust SE)
\end{tabular}

Table 6 displays the results of our models after removing the top 10\% of scores for ELF. Our political variables remain statistically significant and substantively similar to our primary model while, interestingly, HIV prevalence loses statistical significance and substantive power. 
Table 6: Outlier Controls for Ethno-Linguistic Fractionalized

Models Excluding Top 10\% of EthnoLinguistic Fractionalized Countries

\begin{tabular}{lcccc}
\hline \hline & Model 1 & Model 2 & Model 3 & Model 4 \\
\hline Ethno-Lingustic & - & $0.386^{* *}$ & $0.417^{* *}$ & $0.472^{* *}$ \\
Fractionalization & & $(0.377)^{\Omega}$ & $(0.360)$ & $(0.369)$ \\
Veto Points & - & $1.227^{* *}$ & $1.018^{* *}$ & $1.228^{* *}$ \\
& & $(0.086)^{\Omega}$ & $(0.068)^{\Omega}$ & $(0.083)^{\Omega}$ \\
Democracy & - & 0.983 & - & 0.978 \\
& & $(0.021)$ & & $(0.021)$ \\
HIV Prevalence \% & 1.016 & - & 1.018 & 1.020 \\
& $(0.013)$ & & $(0.013)$ & $(0.013)$ \\
GDP Per Capita & $1.011^{* *}$ & - & 1.004 & 1.005 \\
(\$1000 units) & $(0.006)^{\Omega}$ & & $(0.006)^{\Omega}$ & $(0.007)^{\Omega}$ \\
CD4 Guidelines & Included & Included & Included & Included \\
\hline R ${ }^{2}$ & 0.068 & 0.111 & 0.124 & 0.126 \\
Num. events & 170 & 166 & 170 & 166 \\
Num. obs. & 221 & 215 & 221 & 215 \\
Wald test $(\mathrm{df})$ & $8.32(4)$ & $18.91(5)$ & $25.16(6)$ & $25.25(7)$ \\
Wald test p $=$ & 0.08 & 0.00 & 0.00 & 0.00 \\
\hline${ }^{* * *} p<0.01,{ }^{* *} p<0.05,{ }^{*} p<0.10$, hazard ratios, (SE) or $\Omega=($ Robust SE)
\end{tabular}

We also ran models removing the number of veto points a country has in its government.

Table 7 uses a sample population which has eliminated the observations with six veto points (the maximum number of veto points found in any one country). Our political variables remain both substantively and statistically consistent, and HIV burden loses its statistical significance (although its substantive meaning is largely unchanged from our general model). 
Table 7: Outlier Controls for Countries with High Numbers of Veto Points

Models Excluding Top 10\% of Veto Point Countries

\begin{tabular}{lcccc}
\hline \hline & Model 1 & Model 2 & Model 3 & Model 4 \\
\hline Ethno-Lingustic & - & $0.537^{* *}$ & $0.531^{* *}$ & $0.600^{*}$ \\
Fractionalization & & $(0.310)^{\Omega}$ & $(0.311)$ & $(0.316)$ \\
Veto Points & - & $1.201^{* *}$ & $1.172^{* *}$ & $1.214^{* *}$ \\
& & $(0.080)^{\Omega}$ & $(0.065)$ & $(0.078)^{\Omega}$ \\
Democracy & - & 0.987 & - & 0.982 \\
& & $(0.019)$ & & $(0.019)$ \\
HIV Prevalence \% & 1.014 & - & 1.020 & 1.021 \\
& $(0.019)$ & & $(0.012)$ & $(0.012)$ \\
GDP Per Capita & $1.009^{* *}$ & - & 1.003 & 1.004 \\
(\$1000 units) & $(0.005)^{\Omega}$ & & $(0.006)^{\Omega}$ & $(0.006)^{\Omega}$ \\
CD4 Guidelines & Included & Included & Included & Included \\
\hline R ${ }^{2}$ & 0.041 & 0.069 & 0.083 & 0.083 \\
Num. events & 191 & 186 & 191 & 186 \\
Num. obs. & 243 & 236 & 243 & 236 \\
Wald test (df) & $6.02(4)$ & $12.45(5)$ & $17.46(6)$ & $17.27(7)$ \\
Wald test p= & 0.02 & 0.03 & 0.01 & 0.02 \\
\hline
\end{tabular}

${ }^{* * *} p<0.01,{ }^{* *} p<0.05,{ }^{*} p<0.10$, hazard ratios, $(\mathrm{SE})$ or $\Omega=($ Robust $\mathrm{SE})$ 


\section{Appendix B: Interview Participants}

1. Senior Advisor, Care and Treatment, Joint United Nations Programme on HIV/AIDS (UNAIDS) April 3, 2014

2. Senior official, U.S. State Department, April 4, 2016.

3. Senior official, World Health Organization, April 4, 2016.

4. Senior official, World Health Organization (follow up), April 25, 2017.

5. Head of the Department of Global Health, Academic Medical Center (AMC), University of Amsterdam and chair of the ARV Guidelines Committee in the Netherlands. April 4, 2014.

6. Director of the British Columbia Centre for Excellence in HIV/AIDS, Head of Division of AIDS, University of British Columbia. April 3, 2014

7. Chair of the Coordinated Action $\mathrm{n}^{\circ} 12$ of the French Agency for Research on HIV/AIDS and Viral Hepatitis (ANRS), Professor of Epidemiology, University Bordeaux Segalen and Chair of the Scientific Advisory Board of the Institut national de la Veille Sanitaire (French CDC). April 3, 2014.

8. Executive Director, U.S. HIV NGO and member of the HHS Planel on ARVs.

9. Director of the Thai Red Cross AIDS Research Centre (TRC-ARC), Professor of Medicine at Chulalongkorn University. April 4, 2014.

10. National Coordinator, HIV Care and Treatment (ART) Programme in the Ministry of Health, Swaziland. April 3, 2014.

11. Official, Lighthouse Trust, Malawi April 4, 2014.

12. Researcher, The AIDS Support Organization (TASO), Uganda. April 4, 2014.

13. National Coordinator of the PMTCT Programme, Ministry of Health, Uganda. April 3, 2014.

14. President European AIDS Clinical Society Oct 13, 2016.

15. Senior Technical Official, Ministry of Health, Malawi, October 13, 2016.

16. Senior Technical Official, Medical Research Council, Uganda, October 14, 2016.

17. Director of National HIV program for Rwanda, October 13, 2016.

18. Civil soceity leader, Zambia, October 14, 2016.

19. Researcher, Wits Reproductive Health \& HIV Institute, South Africa, July 21, 2016.

20. Official, Anova Health, South Africa, October 13, 2016.

21. Former Head of NACO \& Health Secretary, India, December 1, 2015.

22. Tata Institute and former Health Secretary, India, November 29, 2015.

23. Senior Official, Brazil Ministry of Health, April 27, 2017.

24. Senior NGO leader, Phillipines, May 31, 2017.

25. Senior public health leader, HIV and AIDS Support House, June 2, 2017.

26. Senior official, Ministry of Health and Wellness, Botswana, July 18, 2016. 